\title{
Selective changes to phosphatidylcholine and phosphatidylethanolamine molecular species in the developing fetal guinea pig liver and plasma
}

\author{
Graham C. BURDGE ${ }^{\mathrm{a} *}$, Anthony D. PostLE ${ }^{\mathrm{b}}$ \\ a Institute of Human Nutrition, Developmental Origins of Health and Adult Disease Division, \\ School of Medicine, University of Southampton, Southampton, UK \\ b Allergy and Inflammation Research, Infection, Inflammation and Repair Division, \\ School of Medicine, University of Southampton, Southampton, UK
}

(Received 25 May 2004; accepted 27 July 2004)

\begin{abstract}
The molecular species composition of membrane phospholipids influences the activities of integral proteins and cell signalling pathways. We determined the effect of increasing gestational age on fetal guinea pig liver phosphatidylcholine (PC) and phosphatidylethanolamine (PE), and plasma PC molecular species composition. The livers were collected from fetuses ( $n=5 /$ time point) at 5 day intervals between 40 and 65 days of gestation, and at term (68 days). Hepatic PC and PE molecular species composition was determined by electrospray ionisation mass spectrometry. An increasing gestational age was accompanied by selective changes in individual molecular species. The proportion of the $s n-1$ 18:0 species increased relative to the $s n-1$ 16:0 species in liver PC, but not PE, with an increasing gestational age. 1-O-alkyl-2-acyl PC species concentrations decreased significantly between 40 and 45 days of gestation (40\%), and 65 and 68 days (54\%). Total 1-Oalkenyl-2-acyl PE species concentration increased between days 60 and 65, due to a rise in 1-O-16:0 alkyl/20:4 content, and then decreased until term. Between day 40 and term, PC and PE sn-2 18:2n-6 species concentrations increased 3-fold. PC16:0/18:2 increased gradually throughout gestation, while PC18:0/18:2 content only increased after day 65 . The overall increase in PE18:2n-6 content was due to PE18:0/18:2 alone. The composition of plasma PC essentially reflected hepatic PC. Overall, these data suggest differential regulation of hepatic PC and PE molecular species composition during development which is essentially independent of the maternal fatty acid supply.
\end{abstract}

phospholipids / gestation / electrospray ionisation mass spectrometry / ether phospholipids

\section{INTRODUCTION}

The phospholipid molecular species composition of cell membranes is an important determinant of the biophysical properties of the lipid bilayer. Differences in molecular species composition, particularly in the relative amounts of saturated and polyunsatu- rated species, alter the activities of integral membrane proteins [1-3] and so may modify cell function. The molecular species composition of membrane phospholipids is the net result of the specificity of synthesis de novo from specific diacylglycerol pools [4], the activities of acyl-remodelling mechanisms and selective turnover of individual

\footnotetext{
* Corresponding author: g.c.burdge@ soton.ac.uk
} 
molecular species [5-7]. $\mathrm{N}$-methylation of phosphatidylethanolamine (PE) may also be an important source of phosphatidylcholine (PC), particularly in the liver [8]. Together the activities of these pathways result in tissue-specific membrane phospholipid compositions. This implies tailoring of the biophysical properties of the phospholipid bilayer to the functional requirements of membrane proteins within individual tissues.

Development of the brain is associated with specific temporal changes to PC and $\mathrm{PE}$ molecular species compositions that are largely associated with the accumulation of docosahexaenoic acid (22:6n-3) [9]. In particular, early development is associated with the accumulation of $22: 6 n-3$ into the $s n-1$ palmitoyl PE species while in late gestation $22: 6 n-3$ is preferentially assimilated into the $s n-1$ oleoyl and $s n-1$ stearoyl species. This suggests that the maturation of the fetal guinea pig brain may be associated with increased incorporation of 22:6n-3 into phospholipid molecular species with slower rates of turnover $[6,7]$. In the developing lung there is a progressive decrease in PC16:0/ 18:1 and an increase in PC16:0/16:0 which is associated with the maturation of pulmonary surfactant synthesis [10].

In addition to the synthesis and maintenance of cell membranes, phospholipid biosynthesis in the hepatocyte is critical for the assembly and secretion of VLDL [11]. In adult rats [4] and guinea pigs [12], there is a close correlation between the molecular species composition of hepatic and plasma PC, suggesting that the bulk pool of hepatic $\mathrm{PC}$ is destined for mobilisation into VLDL. Moreover, in addition to its structural role in lipoprotein particles, plasma PC is an important carrier of long-chain polyunsaturated fatty acids (LCPUFA) in the blood and may represent an important mechanism for the supply of LCPUFA from the liver to peripheral tissues.

Evidence suggesting that the composition of hepatic PC and PE, and plasma PC can be modified to meet specific physiological demands associated with fetal and postnatal development has been provided from pregnancy studies in humans [13], rats [4] and guinea pigs [12]. These show selective changes to hepatic and/or plasma phospholipid molecular species compositions, in particular an increased 1-palmitoyl-2-docosahexaenoylPC (PC16:0/22:6) concentration. This may represent one mechanism to facilitate adequate provision of LCPUFA to developing fetal tissues. In the rat, this increased hepatic PC de novo synthesis is accompanied by decreased acyl remodelling of $s n-1$ palmitoyl to $s n-1$ stearoyl PC molecular species by the Lands pathway [4], and the enrichment in PC16:0/22:6 reflects, in part, an increase in the 16:0/22:6 content of the diacylglycerol substrate pool destined for incorporation into PC.

While this evidence supports the hypothesis that adaptations to maternal lipid synthesis are involved in the directed supply of LCPUFA to the developing fetal brain, the contribution of the fetal liver to this process is not clear. The analysis of liver collected from human infants who were either stillborn or died between 3 and 24 weeks of birth showed a signficant increase in hepatic $s n-2$ 18:2n-6 molecular species during early postnatal life [13]. A decline in plasma $22: 6 n-3$ and arachidonic acid (20:4n-6) has also been reported during the first six weeks after birth in human infants [13-16]. Such changes to liver and plasma fatty acid composition have been largely attributed to the major nutritional adaptation from placental to milk feeding and consequently the role of any developmental process independent of nutrition has not been established. The fetal guinea pig represents an ideal model to dissect the relative contributions of nutrition and development on the maturation of fetal liver and plasma phospholipid metabolism. The bulk of fetal cell differentiation and acquisition of cell-specific lipid compositions occur pre-natally and there are minimal changes to maternal guinea pig plasma lipid compositions in late gestation [12].

We hypothesised that the demonstration of co-ordinated changes to the liver and 
plasma phospholipid compositions in the fetal guinea pig, in the absence of altered maternal plasma lipid composition, would support the concept of programmed developmental changes in hepatic phospholipid metabolism. Consequently, we used a highly sensitive electrospray ionisation mass spectrometry (ESI-MS) technique to determine the effect of maturation on the molecular species composition of the developing fetal guinea pig liver $\mathrm{PC}$ and $\mathrm{PE}$, and plasma $\mathrm{PC}$.

\section{MATERIALS AND METHODS}

\subsection{Materials}

HPLC grade methanol was obtained from Rathburn Ltd. (Walkerburn, Scotland). All other solvents were from Merck Ltd. (Poole, Dorset, UK). BondElut solid phase extraction cartridges were from Varian (Waltonon-Thames, Surrey, UK). All other reagents were from Sigma-Aldrich Co. Ltd. (Poole, Dorset, UK).

\subsection{Animal procedures}

Animal procedures were as described previously [12] and were conducted in accordance with the Animals (Scientific Procedures) Act 1986, UK. Briefly, out-bred virgin female guinea pigs were fed a maintenance diet (FD1; Special Diets Services, Witham, Essex, UK) ad libitum before mating and throughout pregnancy (Tab. I). At five day intervals from 40 days gestation and at term, (day 68) fetuses ( $n=5$ per gestational age) were delivered by caesarean section and sacrificed as described [6]. Blood was collected by cardiac puncture using ethylenediamine tetraacetic acid as the anticoagulant; plasma was separated from cells by centrifugation and stored at $-20^{\circ} \mathrm{C}$. The livers were removed, frozen in liquid nitrogen and stored at $-20^{\circ} \mathrm{C}$.

\subsection{Isolation of phospholipids}

Fetal liver (about $100 \mathrm{mg}$ ) was homogenised in $0.9 \%(\mathrm{w} / \mathrm{v}) \mathrm{NaCl}$ using an UltraTurrax homogeniser (Janke and Kunkel,
Table I. Fatty acid composition of the guinea pig diet.

\begin{tabular}{lc}
\hline Fatty acid & $\begin{array}{c}\text { Weight percent } \\
\text { total fatty acids }\end{array}$ \\
\hline Lauric acid (12:0) & 1.4 \\
Myrisitic acid (14:0) & 5.8 \\
Myristoleic acid (14:1) & 1.0 \\
Palmitic acid (16:0) & 12.6 \\
Palmitoleic acid (16:1n-7) & 6.1 \\
Stearic acid (18:0) & 2.4 \\
Oleic acid (18:1n-9) & 23.8 \\
Linoleic acid (18:2n-6) & 22.8 \\
$\alpha$-Linolenic acid (18:3n-3) & 16.3 \\
Arachidonic acid (20:4n-6) & 6.5 \\
Docosapentaenoic acid (22:5n-3) & 1.4 \\
Eicosapentaenoic acid (20:5n-3) & ND \\
Docosahexaenoic acid (22:6n-3) & ND \\
\hline
\end{tabular}

Results of the manufacturer's analysis of the fatty acid composition of the guinea pig maintenance diet (total fat content $8.0 \mathrm{~g} \cdot 100 \mathrm{~g}^{-1}$ feed). ND = not detected.

Staufen, Germany). Total lipids were extracted with chloroform/methanol [17]. Plasma was added dropwise with continual stirring to $2 \mathrm{~mL}$ ice cold methanol, followed by the addition of $0.9 \%(\mathrm{w} / \mathrm{v}) \mathrm{NaCl}$ so that the total volume of plasma and saline was $0.8 \mathrm{~mL}$ [18]. Chloroform $(2.0 \mathrm{~mL})$ was then added and total plasma lipids were isolated [17]. PC and PE were purified by solid phase extraction using aminopropylsilica cartridges $(100 \mathrm{mg})[18,19]$.

\subsection{Analysis of phospholipid molecular species by electrospray ionisation mass spectrometry}

Molecular species compositions of individual phospholipids were analysed by ESI-MS using a Quattro II triple quadrupole mass spectrometer (Micromass UK Ltd., Manchester, UK) as described [20]. Lipid extracts were dissolved in $20 \mu \mathrm{L}$ of chloroform:methanol $(1: 2 \mathrm{v} / \mathrm{v})$ containing $5 \mathrm{mM} \mathrm{NaOH}$ and $5 \mu \mathrm{L}$ introduced by rheodyne valve injection into a flow of methanol:chloroform:water (80:10:10 v/v) pumped 
at $10 \mu \mathrm{L} \cdot \mathrm{min}^{-1}$ into the capillary inlet of the mass spectrometer. PC molecular species were detected as sodiated adducts under positive conditions, $[\mathrm{M}+\mathrm{Na}]^{+}$, while $\mathrm{PE}$ molecular species were detected as their molecular ions under negative conditions, $[\mathrm{M}-\mathrm{H}]^{-}$. Spectra were obtained by signal averaging (typically $1 \mathrm{~min}$ ) and processed using Masslynx software (Micromass UK Ltd., Manchester, UK). Mole percentage abundance of molecular ions was determined after conversion of data to centroid format after correction for the ${ }^{13} \mathrm{C}$ isotope effect.

The results are initially presented in terms of total numbers of carbon atoms and double bonds in the individual molecular species, since each ion peak may contain multiple species. The molecular species identified were the most prominent for each ion, determined by tandem MS/MS product ion scans after collision gas-induced fragmentation under negative ionisation using argon as the collision gas [20, 21]. Ether-linked species were identified on the basis of a combination of generating only a single fatty acyl fragment ion and their resistance (1-Oalkyl-2-acyl, designated A) or susceptibility (1-O-alkenyl-2-acyl, designated P) to hydrolysis by $1 \mathrm{M} \mathrm{HCl}$.

\subsection{Statistical analysis}

Data are presented as fractional concentrations of individual phospholipid molecular species. Comparisons of phospholipid molecular species concentrations between gestational ages were performed by one-way ANOVA with Bonferroni post hoc correction for multiple comparisons.

\section{RESULTS}

\subsection{Hepatic phosphatidylcholine molecular species composition}

Twenty-one PC molecular species and sixteen PE molecular species were identified in the fetal guinea pig liver. $S n-1$ 16:0 and $s n-1$ 18:0 species were the major components of hepatic PC, with smaller amounts of $18: 1 n-9(4.3 \%)$ species. The proportion of $s n-1$ 16:0 species in the fetal guinea pig liver PC at 40 days gestation was approximately twice the content of the $s n-1 \quad 18: 0$ species (Tab. II). An increasing gestational age between 40 days and term was accompanied by a $26.2 \%$ decrease in the $s n-116: 0$ $\mathrm{PC}$ species, an $88 \%$ decrease in the single sn-1 18:1n-9 (PC18:1/20:4) species and a $65.4 \%$ increase in the $s n-1$ 18:0 species (Tab. II). At 40 days gestation, the $s n-1$ alkyl species accounted for $13.7 \%$ of the PC species, of which $9.8 \%$ were the $s n-116: 0$ species and $3.9 \%$ were the $s n-1$ 18:0 species (Tab. II). The proportion of total 1-O-alkyl PC species decreased between days 40 and $45(40 \%)$, then remained essentially unchanged until day 65 , and then decreased by $54 \%$ between day 65 and term (Fig. 1). At term, 1-O-1 16:0 alkyl species accounted for less than $0.1 \%$ of PC molecular species and PC18:0 alkyl/18:1 was $62 \%$ lower at term compared to day 40 .

An increasing gestational age was accompanied by selective changes in the proportions of individual hepatic PC molecular species. The fractional concentrations of the major disaturated species at 40 days gestation PC16:0/16:0 and PC16:0/18:0 decreased progressively throughout gestation (overall changes were $>89 \%$ and $89.8 \%$, respectively), while the proportions of PC16:0/ 14:0 and PC18:0/18:0 did not change, although there was a non-significant trend towards a reduction in PC18:0/18:0 concentration (Tab. II). There were no significant changes in the concentrations of the monounsaturated species PC18:0/18:1 and PC16:0/16:1. The greatest change in PC composition between 40 days gestation and term was the increase in the concentration of the 18:2n-6 species. This occurred in two phases, between days 40 and $45(45.0 \%)$ and day 60 and term (68.7\%) (Fig. 2). This was due to an overall 2.4 fold increase in the fractional concentration of PC16:0/18:2 and a 3.2 fold increase in PC18:0/18:2. At term $s n-2$ 18:2n-6 species accounted for $53.8 \%$ 
Table II. Fetal guinea pig liver phosphatidylcholine molecular species composition.

\begin{tabular}{|c|c|c|c|c|c|c|c|c|c|}
\hline \multirow{3}{*}{$\mathrm{M}_{\mathrm{r}}$} & \multirow{3}{*}{$\begin{array}{c}\text { Total } \\
\text { carbons: } \\
\text { double bonds }\end{array}$} & \multirow{3}{*}{$\begin{array}{c}\text { Predominant } \\
\text { molecular } \\
\text { species }\end{array}$} & \multicolumn{7}{|c|}{ Gestational age (days) } \\
\hline & & & 40 & 45 & 50 & 55 & 60 & 65 & 68 \\
\hline & & & \multicolumn{7}{|c|}{ Fractional concentration (\%) } \\
\hline \multicolumn{10}{|c|}{ Sn-1 16:0 series } \\
\hline 728 & $30: 0$ & $16: 0 / 14: 0$ & $1.5 \pm 0.3$ & $1.3 \pm 0.3$ & $1.5 \pm 0.1$ & $1.2 \pm 0.2$ & $0.9 \pm 0.6$ & $0.4 \pm 0.5$ & $1.1 \pm 0.5$ \\
\hline 756 & $32: 0$ & $16: 0 / 16: 0$ & $7.0 \pm 0.5$ & $5.4 \pm 0.1^{\mathrm{a}}$ & $5.0 \pm 0.4^{\mathrm{a}}$ & $4.1 \pm 0.2^{\mathrm{a}, \mathrm{b}}$ & $4.4 \pm 0.2^{\mathrm{a}, \mathrm{b}}$ & $2.4 \pm 0.1^{\mathrm{a}-\mathrm{e}}$ & $1.6 \pm 0.1^{\mathrm{a}-\mathrm{e}}$ \\
\hline 784 & $34: 0$ & $16: 0 / 18: 0$ & $4.9 \pm 0.8$ & $3.7 \pm 0.2^{\mathrm{a}}$ & $3.0 \pm 0.5^{\mathrm{a}}$ & $2.6 \pm 0.5^{\mathrm{a}}$ & $2.9 \pm 0.5^{\mathrm{a}}$ & $1.4 \pm 0.1^{\mathrm{a}, \mathrm{b}}$ & $0.5 \pm 0.6^{\mathrm{a}-\mathrm{e}}$ \\
\hline 742 & $32: 0 \mathrm{~A}$ & $16: 0 / 16: 0 \mathrm{~A}$ & $0.9 \pm 0.7$ & $0.9 \pm 0.1$ & $1.7 \pm 0.4$ & $0.4 \pm 0.5^{\mathrm{a}-\mathrm{c}}$ & $<0.1^{\mathrm{a}-\mathrm{d}}$ & $<0.1^{\mathrm{a}-\mathrm{d}}$ & $<0.1^{\mathrm{a}-\mathrm{d}}$ \\
\hline 770 & $34: 0 \mathrm{~A}$ & $16: 0 / 18: 0 \mathrm{~A}$ & $2.4 \pm 1.2$ & $0.5 \pm 0.4^{\mathrm{a}}$ & $0.5 \pm 0.4^{\mathrm{a}}$ & $<0.1^{\mathrm{a}, \mathrm{b}}$ & $<0.1^{\mathrm{a}, \mathrm{b}}$ & $<0.1^{\mathrm{a}, \mathrm{b}}$ & $<0.1^{\mathrm{a}, \mathrm{b}}$ \\
\hline 754 & $32: 1$ & $16: 0 / 16: 1$ & $5.0 \pm 1.0$ & $4.0 \pm 0.2$ & $5.0 \pm 0.5$ & $3.4 \pm 0.3$ & $3.4 \pm 0.6$ & $4.1 \pm 0.8$ & $5.1 \pm 1.4$ \\
\hline 740 & $32: 1 \mathrm{~A}$ & $16: 0 / 16: 1 \mathrm{~A}$ & $1.4 \pm 0.1$ & $1.1 \pm 0.1$ & $0.8 \pm 0.5$ & $0.4 \pm 0.6$ & $0.3 \pm 0.4$ & $1.4 \pm 0.3$ & $<0.01^{\mathrm{a}-\mathrm{f}}$ \\
\hline 782 & $34: 1$ & $16: 0 / 18: 1$ & $12.8 \pm 1.7$ & $10.3 \pm 0.4$ & $9.8 \pm 0.5^{\mathrm{a}}$ & $7.8 \pm 0.1^{\mathrm{a}}$ & $8.5 \pm 0.6^{\mathrm{a}}$ & $9.5 \pm 0.2^{\mathrm{a}}$ & $7.5 \pm 0.2^{\mathrm{a}, \mathrm{b}}$ \\
\hline 768 & $34: 1 \mathrm{~A}$ & $16: 0 / 18: 1 \mathrm{~A}$ & $5.1 \pm 1.9$ & $3.2 \pm 0.2$ & $3.2 \pm 0.5$ & $2.3 \pm 0.2$ & $3.3 \pm 0.6$ & $3.0 \pm 0.9$ & $1.7 \pm 0.2^{\mathrm{a}}$ \\
\hline 780 & $34: 2$ & $16: 0 / 18: 2$ & $7.7 \pm 1.4$ & $9.4 \pm 0.2$ & $10.1 \pm 0.6$ & $9.8 \pm 0.3$ & $9.5 \pm 0.7$ & $16.6 \pm 1.0^{\mathrm{a}-\mathrm{e}}$ & $18.2 \pm 1.0^{\mathrm{a}-\mathrm{e}}$ \\
\hline 806 & $36: 3$ & $16: 0 / 20: 3$ & $7.0 \pm 1.2$ & $8.4 \pm 0.1$ & $6.3 \pm 1.0$ & $6.4 \pm 0.1$ & $5.9 \pm 0.4$ & $5.2 \pm 0.3$ & $6.8 \pm 0.7$ \\
\hline 804 & $36: 4$ & $16: 0 / 20: 4$ & $5.1 \pm 0.1$ & $4.6 \pm 0.2$ & $4.1 \pm 0.1$ & $4.6 \pm 0.3$ & $4.5 \pm 0.3$ & $4.1 \pm 0.3$ & $3.8 \pm 1.1$ \\
\hline 828 & $38: 6$ & $16: 0 / 22: 6$ & $3.4 \pm 0.6$ & $3.2 \pm 0.1$ & $2.6 \pm 0.6$ & $4.1 \pm 0.2$ & $4.3 \pm 0.6$ & $4.2 \pm 0.5$ & $1.1 \pm 0.8^{\mathrm{a}-\mathrm{f}}$ \\
\hline & & Total & $62.7 \pm 3.9$ & $54.7 \pm 0.6^{\mathrm{a}}$ & $52.4 \pm 1.7^{\mathrm{a}}$ & $45.8 \pm 1.5^{\mathrm{a}}$ & $47.0 \pm 2.3^{\mathrm{a}}$ & $5.2 \pm 2.0^{\mathrm{a}}$ & $46.3 \pm 0.5^{\mathrm{a}}$ \\
\hline \multicolumn{10}{|c|}{$S n-1$ 18:0 series } \\
\hline 816 & $36: 0$ & 18:0/18:0 & $2.2 \pm 0.9$ & $1.5 \pm 0.4$ & $1.2 \pm 1.1$ & $1.1 \pm 0.0$ & $0.9 \pm 0.1$ & $0.3 \pm 0.5$ & $0.5 \pm 0.7$ \\
\hline 810 & $36: 1$ & $18: 0 / 18: 1$ & $6.7 \pm 0.6$ & $7.1 \pm 0.3$ & $7.7 \pm 0.1$ & $7.8 \pm 0.5$ & $8.1 \pm 0.1$ & $8.2 \pm 0.3$ & $7.4 \pm 0.2$ \\
\hline 796 & $36: 1 \mathrm{~A}$ & $18: 0 / 18: 1 \mathrm{~A}$ & $3.9 \pm 0.8$ & $2.7 \pm 0.3$ & $3.2 \pm 0.5$ & $2.5 \pm 0.2$ & $2.5 \pm 0.3$ & $2.5 \pm 0.1$ & $1.5 \pm 1.1$ \\
\hline 808 & $36: 2$ & $18: 0 / 18: 2$ & $11.2 \pm 1.6$ & $18.0 \pm 0.3^{\mathrm{a}}$ & $21.1 \pm 0.4^{\mathrm{a}, \mathrm{b}}$ & $24.0 \pm 0.4^{\mathrm{a}, \mathrm{b}}$ & $22.4 \pm 0.7^{\mathrm{a}, \mathrm{b}}$ & $25.2 \pm 0.8^{\mathrm{a}-\mathrm{c}}$ & $35.6 \pm 1.4^{\mathrm{a}-\mathrm{f}}$ \\
\hline 850 & $38: 3$ & $18: 0 / 20: 3$ & $0.6 \pm 0.4$ & $0.5 \pm 0.3$ & $0.3 \pm 0.4$ & $<0.1^{\mathrm{a}-\mathrm{c}}$ & $<0.1^{\mathrm{a}-\mathrm{c}}$ & $<0.1^{\mathrm{a}-\mathrm{c}}$ & $<0.1^{\mathrm{a}-\mathrm{c}}$ \\
\hline 832 & $38: 4$ & $18: 0 / 20: 4$ & $4.8 \pm 1.4$ & $6.5 \pm 0.3$ & $5.9 \pm 0.7$ & $8.1 \pm 0.4^{\mathrm{a}-\mathrm{c}}$ & $8.4 \pm 1.0^{\mathrm{a}-\mathrm{c}}$ & $5.2 \pm 0.8^{\mathrm{d}, \mathrm{e}}$ & $3.8 \pm 1.1^{\mathrm{b}, \mathrm{d}, \mathrm{e}}$ \\
\hline 856 & $40: 6$ & $18: 0 / 22: 6$ & $2.1 \pm 0.8$ & $3.4 \pm 0.1$ & $3.2 \pm 0.6$ & $5.8 \pm 0.5^{\mathrm{a}-\mathrm{c}}$ & $6.2 \pm 1.3^{\mathrm{a}-\mathrm{c}}$ & $4.2 \pm 0.7^{\mathrm{d}, \mathrm{e}}$ & $1.6 \pm 0.2^{\mathrm{a}-\mathrm{f}}$ \\
\hline & & Total & $31.5 \pm 3.4$ & $39.5 \pm 1.1^{\mathrm{a}}$ & $42.5 \pm 1.5^{\mathrm{a}}$ & $49.1 \pm 1.6^{\mathrm{a}}$ & $48.5 \pm 1.9^{a}$ & $45.6 \pm 2.0^{\mathrm{a}}$ & $52.1 \pm 1.8^{\mathrm{a}-\mathrm{c}, \mathrm{f}}$ \\
\hline \multicolumn{10}{|c|}{ Sn-1 18:1n-9 series } \\
\hline 830 & $38: 5$ & $18: 1 / 20: 4$ & $4.3 \pm 0.6$ & $4.4 \pm 0.2$ & $3.6 \pm 0.3$ & $3.9 \pm 0.1$ & $3.6 \pm 0.9$ & $2.0 \pm 0.1^{\mathrm{a}-\mathrm{e}}$ & $0.5 \pm 0.8^{\mathrm{a}-\mathrm{f}}$ \\
\hline
\end{tabular}

The results of the analysis of fetal guinea pig liver phosphatidylcholine molecular species composition by electrospray mass spectrometry. Values are mean \pm SD for $n=5$ fetuses. The results which differed significantly $(P<0.05)$ from preceding time points in gestation are indicated as follows: a different from day 40 ;

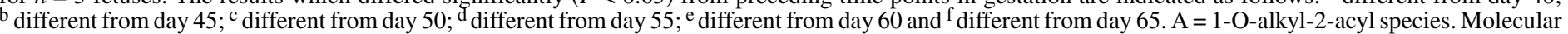
species comprising less than $0.1 \%$ of total were regarded as being too close to the detection limit for precise measurement. 


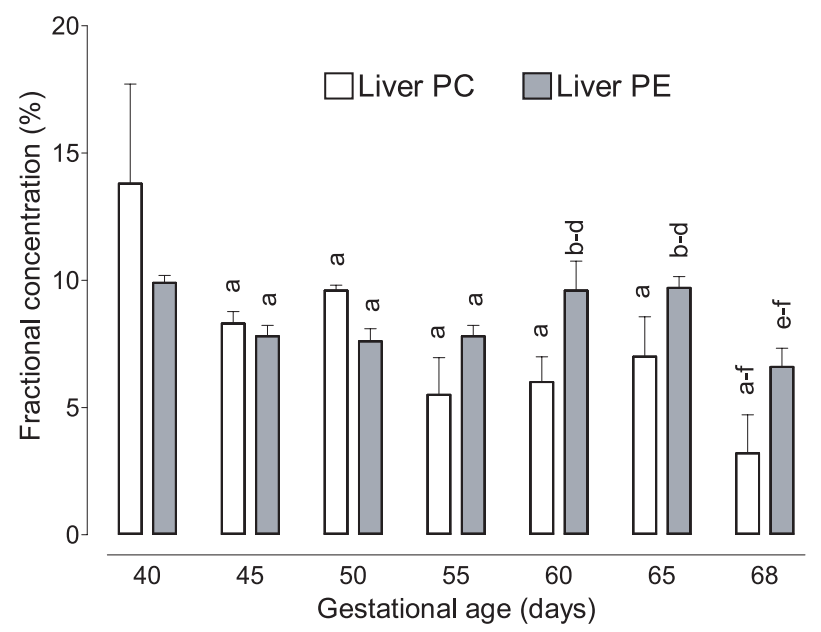

Figure 1. Total (mean $\pm \mathrm{SD}$ ) fractional concentrations of 1-O-alkyl-2-acyl PC and 1-O-alkenyl-2acyl PE molecular species in fetal guinea pig liver PC and PE, respectively $(n=5$ at each gestational age). The results which differed significantly $(P<0.05)$ from preceding time points in gestation are indicated as follows: ${ }^{\mathrm{a}}$ different from day $40 ;{ }^{\mathrm{b}}$ different from day $45 ;{ }^{\mathrm{c}}$ different from day 50 ; ${ }^{\mathrm{d}}$ different from day $55 ;{ }^{\mathrm{e}}$ different from day 60 and ${ }^{\mathrm{f}}$ different from day 65.

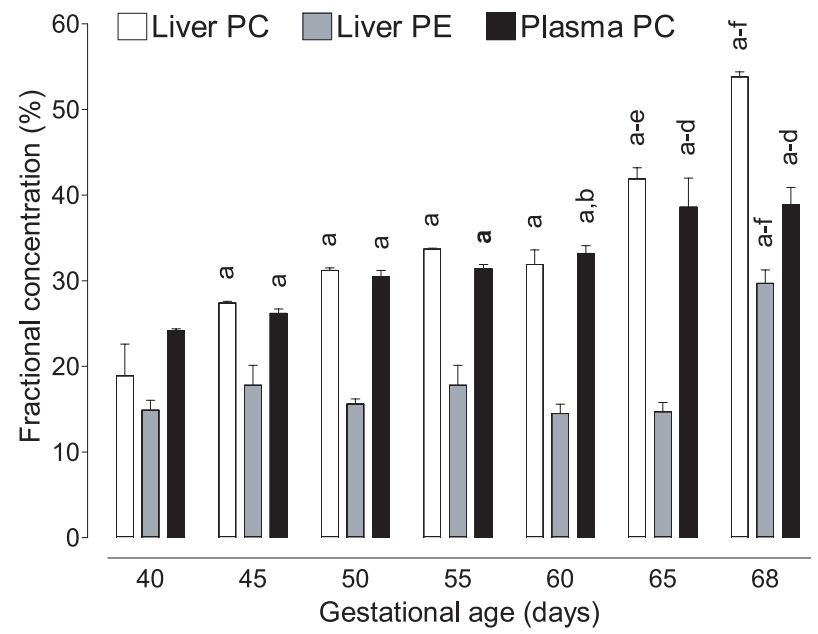

Figure 2. Total (mean \pm SD) fractional concentrations of $s n-2$ 18:2n-6 molecular species in fetal guinea pig liver PC and PE, and plasma PC ( $n=5$ at each gestational age). The results which differed significantly $(P<0.05)$ from preceding time points in gestation are indicated as follows: ${ }^{\mathrm{a}}$ different from day $40 ;{ }^{\mathrm{b}}$ different from day $45 ;{ }^{\mathrm{c}}$ different from day $50 ;{ }^{\mathrm{d}}$ different from day 55; ${ }^{\mathrm{e}}$ different from day 60 and ${ }^{\mathrm{f}}$ different from day 65 .

of total hepatic PC species compared with $18.9 \%$ at day 40 (Tab. II). Significant accumulation of 18:2n-6 into PC18:0/18:2 occurred throughout gestation, whereas there was no significant increase in PC16:0/18:2 until day 65 . The fractional concentrations of PC16:0/20:3, PC16:0/20:4 and PC16:0/ 22:6 (Tab. II) did not change during gestation, while the proportion of PC18:0/20:3 concentration decreased to less than $0.1 \%$, 
and the fractional concentrations of $\mathrm{PC} 18: 0 /$ 20:4, PC18:1/20:4 and PC18:0/22:6 concentrations decreased by $53.1 \%, 87.2 \%$ and $72.4 \%$, respectively, between day 55 and term.

\subsection{Hepatic phosphatidylethanolamine molecular species composition}

At day 40, hepatic PE contained 2.5 fold more $s n-1$ 18:0 PE species compared to $s n-1$ 16:0 species, while $s n-116: 1 n-7$ and 18:1n-9 species accounted for $21 \%$ of the PE species (Tab. III). There was no significant change in the fractional concentrations of the $s n-1$ 16:0 and $s n-1$ 18:0 PE species between day 40 and term although there was a trend towards decreased $s n-1$ 16:0 and increased $s n-1$ 18:0 contents, while the proportion of $s n-116: 1 \mathrm{n}-7$ and $s n-118: 1 n-9$ species decreased by $20.4 \%$ and $28.9 \%$, respectively. The 1-O-1 alkenyl species accounted for $10 \%$ of total PE species at day 40 and $7 \%$ at term (Tab. III). However, total 1-O-alkenyl PE species concentration increased transiently between days 55 and 60 (23\%), due to an increase in 16:0 alkenyl/20:4 concentration (Tab. III), and then decreased between day 65 and term (32\%) (Fig. 1).

There was no change in the proportions of PE16:1/18:3, PE 16:0/18:1, PE16:0 alkenyl/20:4, PE 18:0/18:1, PE18:0/22:5 and PE18:1/18:2 between 40 and 68 days of gestation (Tab. III). There were overall decreases in the concentrations of PE16:0/20:4 between day 60 and term (16.7\%), PE18:0/20:4 between day 60 and term (24.5\%), PE18:0/ $22: 4$ between day 65 and term $(30.0 \%)$ and PE18:1/20:4 between day 40 and term $(45.3 \%)$. Although there was no change in the proportion of PE18:0/22:6, PE16:0/ $22: 6$ increased by $46.0 \%$ between day 55 and day 60 , but decreased $(42.4 \%)$ to a similar level between day 65 and term (Tab. III). Although PE16:0/18:2 concentration did not change between day 40 and term, the proportion of PE18:0/18:2 increased by $87.0 \%$ between day 65 and term (Tab. III and Fig. 2).

\subsection{Plasma phosphatidylcholine molecular species composition}

Plasma PC was composed of 14 molecular species. There was a greater proportion (approximately 1.5 fold) of the $s n-116: 0$ species compared to the $s n-1$ 18:0 species throughout gestation, while the content of the single $s n-1$ 18:1n-9 species (PC18:1/ 20:4) decreased by $47 \%$ between day 50 and term (Tab. IV). There was no change in the concentrations of the $s n-116: 0$ species PC16:0/16:0, PC16:0/16:1, PC16:0/18:1, PC16:0 alkyl/ 18:1, PC16:0/20:3, PC16:0/ 20:4, PC16:0/22:6 between 40 and 68 days of gestation (Tab. IV). Increasing gestational age was accompanied by the disappearance of PC16:0/18:0 after 55 days of gestation and an overall reduction in PC18:0/ 20:4 between day 60 and term $(33.8 \%)$ and 18:1/20:4 (38.5\%) between day 45 and term (Tab. IV). PC16:0/18:2 increased by $39.8 \%$ between day 55 and term and PC18:0/18:2 by $28.4 \%$ between 45 days gestation and term and total $s n-2$ 18:2n-6 species concentration increased from $24 \%$ at day 40 to $39 \%$ of total PC molecular species at term (Tab. IV and Fig. 2). Although there was no change in PC16:0/22:6 concentration between day 40 and term, PC18:0/22:6 concentration decreased $(26.7 \%)$ significantly between day 60 and day 68 .

\section{DISCUSSION}

The molecular species compositions of hepatic PC and PE, and plasma PC presented here were in broad agreement with our previous results of the analysis of late gestation fetal and adult guinea pig liver by HPLC [4, 6, 12]. However, the current analysis by ESI-MS shows that the variety of molecular species present in each phospholipid pool was greater than that reported previously. This emphasises the need for high-resolution analysis to fully characterise membrane phospholipid composition. While the concentration of 22:6n-3 per gram liver tissue increases during development 
Table III. Fetal guinea pig liver phosphatidylethanolamine molecular species composition.

\begin{tabular}{|c|c|c|c|c|c|c|c|c|c|}
\hline \multirow{3}{*}{$M_{r}$} & \multirow{3}{*}{$\begin{array}{c}\text { Total } \\
\text { carbons: } \\
\text { double bonds }\end{array}$} & \multirow{3}{*}{$\begin{array}{c}\text { Predominant } \\
\text { molecular } \\
\text { species }\end{array}$} & \multicolumn{7}{|c|}{ Gestational age (days) } \\
\hline & & & 40 & 45 & 50 & 55 & 60 & 65 & 68 \\
\hline & & & \multicolumn{7}{|c|}{ Fractional concentration $(\%)$} \\
\hline \multicolumn{10}{|c|}{$S n-1$ 16:1n-7 series } \\
\hline 670 & $32: 2 \mathrm{P}$ & $16: 1 / 16: 1 \mathrm{P}$ & $3.4 \pm 0.6$ & $1.5 \pm 0.2^{\mathrm{a}}$ & $1.6 \pm 0.2^{\mathrm{a}}$ & $1.5 \pm 02^{\mathrm{a}}$ & $1.5 \pm 0.3^{\mathrm{a}}$ & $1.4 \pm 0.6^{\mathrm{a}}$ & $1.5 \pm 0.3^{\mathrm{a}}$ \\
\hline 712 & $34: 3$ & $16: 1 / 18: 3$ & $6.4 \pm 2.3$ & $5.2 \pm 1.1$ & $6.7 \pm 0.4$ & $5.2 \pm 1.1$ & $6.0 \pm 1.4$ & $7.7 \pm 3.0$ & $6.4 \pm 1.6$ \\
\hline 716 & $34: 1$ & 16:0/18:1 & $2.8 \pm 0.1$ & $2.9 \pm 0.2$ & $2.6 \pm 0.1$ & $2.9 \pm 0.2$ & $2.4 \pm 0.2$ & $2.2 \pm 0.1$ & $2.6 \pm 0.2$ \\
\hline 714 & $34: 2$ & $16: 0 / 18: 2$ & $5.4 \pm 0.2$ & $4.9 \pm 0.5$ & $4.9 \pm 0.1$ & $4.9 \pm 0.5$ & $5.1 \pm 0.6$ & $6.5 \pm 1.1$ & $7.5 \pm 0.9$ \\
\hline 738 & $36: 4$ & $16: 0 / 20: 4$ & $4.9 \pm 0.2$ & $4.7 \pm 0.2$ & $5.4 \pm 0.6$ & $4.7 \pm 0.2$ & $4.2 \pm 0.6$ & $3.5 \pm 0.1^{\mathrm{a}-\mathrm{d}}$ & $3.5 \pm 0.1^{\mathrm{a}-\mathrm{e}}$ \\
\hline 722 & $36: 4 \mathrm{P}$ & $16: 0 / 20: 4 \mathrm{P}$ & $2.4 \pm 0.5$ & $2.9 \pm 0.5$ & $2.6 \pm 0.3$ & $2.9 \pm 0.5$ & $4.2 \pm 0.4^{\mathrm{a}-\mathrm{d}}$ & $3.6 \pm 0.5^{\mathrm{a}-\mathrm{d}}$ & $2.8 \pm 1.0$ \\
\hline \multirow[t]{3}{*}{762} & $38: 6$ & $16: 0 / 22: 6$ & $8.9 \pm 0.1$ & $8.7 \pm 0.7$ & $8.7 \pm 0.2$ & $8.7 \pm 0.7$ & $12.7 \pm 3.0^{\mathrm{a}-\mathrm{d}}$ & $12.5 \pm 1.0^{\mathrm{a}-\mathrm{d}}$ & $7.2 \pm 0.3^{\mathrm{d}, \mathrm{e}}$ \\
\hline & & Total & $24.5 \pm 0.8$ & $19.2 \pm 1$ & $20.2 \pm 0.6$ & $19.2 \pm 1.1$ & $21.6 \pm 1.7$ & $22.6 \pm 5.0$ & $21.6 \pm 2.5$ \\
\hline & $S n-1$ 18:0 s & & & & & & & & \\
\hline 744 & $36: 1$ & 18:0/18:1 & $3.2 \pm 0.3$ & $4.0 \pm 0.5$ & $3.4 \pm 0.5$ & $4.0 \pm 0.5$ & $3.5 \pm 0.3$ & $3.6 \pm 0.4$ & $4.2 \pm 0.5$ \\
\hline 742 & $36: 2$ & $18: 0 / 18: 2$ & $6.1 \pm 1.0$ & $9.1 \pm 1.7$ & $6.8 \pm 0.2$ & $9.1 \pm 1.7$ & $6.7 \pm 0.5$ & $9.2 \pm 0.5$ & $17.2 \pm 0.5^{\mathrm{a}-\mathrm{f}}$ \\
\hline 766 & $38: 4$ & 18:0/20:4 & $14.5 \pm 0.7$ & $15.7 \pm 1.4$ & $14.9 \pm 0.5$ & $15.7 \pm 1.4$ & $14.3 \pm 2.2$ & $9.8 \pm 1.7^{\mathrm{a}-\mathrm{e}}$ & $10.8 \pm 1.3^{\mathrm{a}-\mathrm{e}}$ \\
\hline 748 & $38: 4 \mathrm{P}$ & 18:0/20:4P & $4.0 \pm 0.2$ & $3.4 \pm 0.1$ & $3.4 \pm 0.3$ & $3.4 \pm 0.1$ & $4.0 \pm 0.3$ & $2.7 \pm 0.2^{\mathrm{a}-\mathrm{e}}$ & $2.3 \pm 0.3^{\mathrm{a}-\mathrm{e}}$ \\
\hline 794 & $40: 4$ & $18: 0 / 22: 4$ & $7.9 \pm 2.3$ & $7.2 \pm 3.1$ & $7.8 \pm 2.6$ & $7.2 \pm 3.1$ & $7.1 \pm 2.6$ & $6.0 \pm 1.0$ & $4.2 \pm 0.3^{\mathrm{a}-\mathrm{e}}$ \\
\hline 792 & $40: 5$ & $18: 0 / 22: 5$ & $9.5 \pm 0.3$ & $9.1 \pm 0.1$ & $9.4 \pm 0.3$ & $9.1 \pm 0.1$ & $9.2 \pm 1.3$ & $9.8 \pm 2.2$ & $9.3 \pm 0.4$ \\
\hline \multirow[t]{3}{*}{790} & $40: 6$ & $18: 0 / 22: 6$ & $9.6 \pm 0.3$ & $10.1 \pm 0.8$ & $10.4 \pm 0.3$ & $10.1 \pm 0.8$ & $13.0 \pm 2.8$ & $13.4 \pm 2.2$ & $11.4 \pm 1.0$ \\
\hline & & Total & $62.3 \pm 2.4$ & $67.3 \pm 5.0$ & $65.0 \pm 3.0$ & $67.0 \pm 5.0$ & $69.5 \pm 4.3$ & $66.5 \pm 6.8$ & $69.1 \pm 3.0^{\mathrm{a}}$ \\
\hline & Sn-1 18:1n-9 & & & & & & & & \\
\hline 740 & $36: 3$ & $18: 1 / 18: 2$ & $3.4 \pm 0.1$ & $3.8 \pm 0.4$ & $3.9 \pm 0.2$ & $3.8 \pm 0.4$ & $2.9 \pm 0.7$ & $3.1 \pm 0.2$ & $5.0 \pm 0.5$ \\
\hline 764 & $38: 5$ & $18: 1 / 20: 4$ & $7.5 \pm 0.1$ & $6.9 \pm 0.8$ & $7.5 \pm 0.4$ & $6.9 \pm 0.8$ & $7.1 \pm 1.4$ & $5.1 \pm 0.6$ & $4.1 \pm 0.2^{\mathrm{a}-\mathrm{e}}$ \\
\hline
\end{tabular}

The results of the analysis of fetal guinea pig liver phosphatidylethanolamine molecular species composition by electrospray mass spectrometry. Values are mean \pm SD for $n=4$ fetuses. The results which differed significantly $(P<0.05)$ from preceding time points in gestation are indicated as follows: ${ }^{\text {a }}$ different from day $40,{ }^{\mathrm{b}}$ different from day $45,{ }^{\mathrm{c}}$ different from day $50,{ }^{\mathrm{d}}$ different from day $55,{ }^{\mathrm{e}}$ different from day $60,{ }^{\mathrm{f}}$ different from day 65 . $\mathrm{P}=1-\mathrm{O}$-alkenyl-2-acyl species. Molecular species comprising less than $0.1 \%$ of total were regarded as too close to the detection limit for precise measurement. 
Table IV. Fetal guinea pig plasma phosphatidylcholine molecular species composition.

\begin{tabular}{|c|c|c|c|c|c|c|c|c|c|}
\hline \multirow{3}{*}{$\mathrm{M}_{\mathrm{r}}$} & \multirow{3}{*}{$\begin{array}{c}\text { Total } \\
\text { carbons: } \\
\text { double bonds }\end{array}$} & \multirow{3}{*}{$\begin{array}{l}\text { Predominant } \\
\text { molecular } \\
\text { species }\end{array}$} & \multicolumn{7}{|c|}{ Gestational age (days) } \\
\hline & & & 40 & 45 & 50 & 55 & 60 & 65 & 68 \\
\hline & & & \multicolumn{7}{|c|}{ Fractional concentration $(\%)$} \\
\hline \multicolumn{10}{|c|}{ Sn-1 16:0 series } \\
\hline 756 & $32: 0$ & $16: 0 / 16: 0$ & $6.1 \pm 1.7$ & $4.0 \pm 0.2$ & $3.3 \pm 0.0$ & $2.4 \pm 0.9$ & $1.5 \pm 2.1$ & $5.1 \pm 2.2$ & $3.1 \pm 0.2$ \\
\hline 784 & $34: 0$ & $16: 0 / 18: 0$ & $2.3 \pm 1.6$ & $2.7 \pm 0.3$ & $2.2 \pm 0.2$ & $2.5 \pm 0.1$ & $<0.01^{\mathrm{a}-\mathrm{d}}$ & $<0.01^{\mathrm{a}-\mathrm{d}}$ & $<0.01^{\mathrm{a}-\mathrm{d}}$ \\
\hline 754 & $32: 1$ & $16: 0 / 16: 1$ & $5.9 \pm 1.7$ & $8.4 \pm 0.2$ & $9.1 \pm 0.1$ & $8.9 \pm 0.2$ & $8.8 \pm 0.4$ & $5.2 \pm 3.8$ & $5.1 \pm 3.8$ \\
\hline 782 & $34: 1$ & 16:0/18:1 & $8.9 \pm 0.6$ & $6.7 \pm 0.3$ & $6.4 \pm 0.3$ & $5.9 \pm 0.4$ & $8.1 \pm 0.3$ & $9.3 \pm 0.9$ & $9.4 \pm 0.5$ \\
\hline 768 & $34: 1 \mathrm{~A}$ & $16: 0 / 18: 1 \mathrm{~A}$ & $12.7 \pm 1.9$ & $10.9 \pm 0.8$ & $11.3 \pm 2.5$ & $10.4 \pm 0.6$ & $11.0 \pm 2.1$ & $9.1 \pm 0.7$ & $8.8 \pm 0.5$ \\
\hline 780 & $34: 2$ & $16: 0 / 18: 2$ & $9.4 \pm 0.4$ & $9.3 \pm 0.2$ & $11.1 \pm 0.4$ & $12.3 \pm 0.9$ & $13.8 \pm 1.6^{\mathrm{a}-\mathrm{c}}$ & $17.3 \pm 1.8^{\mathrm{a}-\mathrm{e}}$ & $17.2 \pm 1.2^{\mathrm{a}-\mathrm{e}}$ \\
\hline 806 & $36: 3$ & $16: 0 / 20: 3$ & $6.3 \pm 0.3$ & $6.9 \pm 0.0$ & $5.4 \pm 02$ & $5.5 \pm 0.1$ & $5.1 \pm 0.2$ & $5.9 \pm 0.4$ & $6.0 \pm 0.7$ \\
\hline 804 & $36: 4$ & $16: 0 / 20: 4$ & $4.9 \pm 0.0$ & $4.6 \pm 0.1$ & $4.4 \pm 0.2$ & $4.7 \pm 0.1$ & $4.8 \pm 0.2$ & $4.2 \pm 0.2$ & $4.2 \pm 0.4$ \\
\hline \multirow[t]{2}{*}{828} & $38: 6$ & $16: 0 / 22: 6$ & $3.8 \pm 0.2$ & $3.4 \pm 0.1$ & $3.3 \pm 0.1$ & $4.0 \pm 0.1$ & $4.0 \pm 0.2$ & $3.7 \pm 0.6$ & $4.3 \pm 0.6$ \\
\hline & & Total & $60.3 \pm 1.6$ & $56.9 \pm 0.1$ & $56.5 \pm 1.7$ & $56.7 \pm 0.8$ & $557.2 \pm 2.3$ & $59.8 \pm 3.2$ & $58.3 \pm 3.5$ \\
\hline \multicolumn{10}{|c|}{$S n-1$ 18:0 series } \\
\hline 810 & $36: 1$ & 18:0/18:1 & $6.6 \pm 0.3$ & $6.6 \pm 0.3$ & $6.4 \pm 0.1$ & 7. \pm 0.1 & $6.8 \pm 0.3$ & $7.8 \pm 0.8$ & $7.7 \pm 0.1$ \\
\hline 808 & $36: 2$ & $18: 0 / 18: 2$ & $14.8 \pm 0.2$ & $16.9 \pm 0.3$ & $19.4 \pm 0.3^{\mathrm{a}, \mathrm{b}}$ & $19.2 \pm 0.4^{\mathrm{a}, \mathrm{b}}$ & $19.3 \pm 1.2^{\mathrm{a}, \mathrm{b}}$ & $21.3 \pm 1.8^{\mathrm{a}, \mathrm{b}}$ & $21.7 \pm 0.8^{\mathrm{a}, \mathrm{b}}$ \\
\hline 832 & $38: 4$ & $18: 0 / 20: 4$ & $7.8 \pm 0.2$ & $7.8 \pm 0.1$ & $6.8 \pm 0.3$ & $7.3 \pm 0.2$ & $7.1 \pm 0.4$ & $4.3 \pm 0.7^{\mathrm{a}-\mathrm{e}}$ & $4.7 \pm 1.0^{\mathrm{a}-\mathrm{e}}$ \\
\hline \multirow[t]{3}{*}{856} & $40: 6$ & 18:0/22:6 & $4.4 \pm 0.2$ & $4.5 \pm 0.2$ & $4.5 \pm 0.2$ & $6.2 \pm 0.1^{\mathrm{a}-\mathrm{c}}$ & $6.0 \pm 0.2^{\mathrm{a}-\mathrm{c}}$ & $3.8 \pm 0.9^{\mathrm{d}, \mathrm{e}}$ & $4.4 \pm 1.0^{\mathrm{d}, \mathrm{e}}$ \\
\hline & & Total & $39.7 \pm 1.6$ & $41.1 \pm 0.2$ & $41.3 \pm 1.5$ & $43.3 \pm 0.8$ & $42.8 \pm 2.3$ & $40.1 \pm 3.2$ & $41.7 \pm 3.5$ \\
\hline & $S n-118: 1_{1}$ & eries & & & & & & & \\
\hline 830 & $38: 5$ & $18: 1 / 20: 4$ & $6.0 \pm 0.6$ & $5.2 \pm 0.1$ & $4.1 \pm 0.4^{\mathrm{a}, \mathrm{b}}$ & $3.6 \pm 0.3^{a, b}$ & $3.6 \pm 0.2^{\mathrm{a}, \mathrm{b}}$ & $2.9 \pm 0.6^{\mathrm{a}, \mathrm{b}}$ & $3.2 \pm 0.6^{\mathrm{a}, \mathrm{b}}$ \\
\hline
\end{tabular}

The results of the analysis of fetal guinea pig plasma phosphatidylcholine molecular species composition by electrospray mass spectrometry. Values are mean \pm SD for $n=4$ fetuses. The results which differed significantly $(P<0.05)$ from preceding time points in gestation are indicated as follows: a different from day 40 , ${ }^{\mathrm{b}}$ different from day $45,{ }^{\mathrm{c}}$ different from day $50,{ }^{\mathrm{d}}$ different from day $55,{ }^{\mathrm{e}}$ different from day $60,{ }^{\mathrm{f}}$ different from day 65 . A $=1$-O-alkyl-2-acyl species. 
[12], the present results indicate that the proportion of 22:6n-3 in the lipid bilayer decreased, primarily due to the substantial increase in the fractional concentration of $18: 2 n-6$.

The results of this study show that an increasing gestational age was accompanied by specific changes to the phospholipid molecular species composition of fetal guinea pig liver and plasma, in particular altered fractional concentrations of linoleic acid-containing species and ether phospholipids. There was no significant change in the fractional concentration of 18:2n-6-containing molecular species in maternal plasma PC between 35 and 68 days of gestation [12]. This suggests that the relative availability of linoleic acid within plasma phospholipid for transfer to the fetus did not change during this period. Fetal liver maturation was associated with an increase in the concentration of $s n-218: 2 \mathrm{n}-6$ PC and PE species, although the precise timing of such changes was dependent upon whether 16:0 or 18:0 was esterified at the $s n-1$ position. One possible explanation is that the incorporation of 18:2n-6 into fetal liver PC and $\mathrm{PE}$ reflects developmental changes to the biosynthesis of these phospholipids independent of maternal supply. Although it is possible that there may be selective modifications to the $18: 2 n-6$ content of other maternal lipid classes which may increase 18:2n-6 availability to the fetus, such adaptations would not explain the differential changes in the $s n-1 \quad 16: 0$ and $s n-1$ 18:0 species between PC and PE.

There were specific changes in the concentrations of 1-O-alkyl-2-acyl PC species and 1-O-alkenyl-2-acyl PE species. Since ether phospholipid biosynthesis occurs in peroxisomes [22], the maturation-associated changes to the concentrations of ether lipids in the fetal liver, including differential effects on 1-O-16:0 1-O-18:0 etherlinked species, cannot be attributed to variations in the maternal fatty acid supply. The decrease in the concentrations of 1-Oalkyl or alkenyl species may reflect a gen- eralised down-regulation of peroxisomal function or decreased alkyl dihydroxyacetonephosphate (DHAP) synthase or acyl/alkyl DHAP reductase activities. Overall, these data support the hypothesis that the maturation of the fetal liver is associated with programmed changes to membrane phospholipids which are independent of maternal fatty acid supply.

The developmental changes in the molecular species composition of plasma PC, primarily VLDL, reflected that of hepatic PC. This suggests that the composition of PC destined for incorporation into cell membranes or secretion was regulated by the same developmental processes and/ or was derived from the same pool. Transport of LCPUFA by plasma PC may represent an important mechanism for the supply of these fatty acids to peripheral tissues. Thus changes to fetal plasma PC molecular species composition during gestation may provide one means of regulating or facilitating the supply of specific fatty acids to meet the demands of developing tissues.

Selective changes in phospholipid molecular species composition have been reported previously in developing lungs [10] and brains [9] and are thus in general agreement with the present data. Phospholipid composition is the net result of the specificity of biosynthesis de novo, acyl remodelling pathways and differential turnover of individual molecular species. In the adult rat $[23,24]$ and adolescent monkey [25] phospholipid composition is modified dramatically by changes in hormonal status. It is possible that, at least in part, the developmental changes in the guinea pig liver phospholipid composition may reflect alterations to the hormonal status of the intra-uterine environment.

The functional significance of developmental changes to hepatic phospholipid composition remains to be determined. Modifications of the fatty acid composition of cell membranes is associated with altered function of integral membrane proteins $[1,2,26]$ 
and the production of lipid mediators including eicosanoids. Thus developmental changes in the phospholipid molecular species composition of hepatic membranes may modify signalling mechanisms. 1-O-alkyl-2-acyl PC and 1-O-alkenyl-2-acyl PE are important regulators of cell function. For example, alkyl/acyl PC is a substrate for the synthesis of the platelet activating factor which, in turn, regulates cell growth and differentiation [27, 28]. Since higher alkyl/acyl PC concentrations are associated with active hepatic cell division, the decrease in the concentrations of total PC and PE etherlinked species in maturing fetal liver may be associated with a reduction in cell division.

These results indicate that the composition of hepatic and plasma phospholipids is programmed during development. One possible interpretation of postnatal changes in the human liver phospholipid molecular species [13] and plasma fatty acid [14-16] compositions, in addition to the effects of commencement of oral feeding, is changes to the specificity of fetal hepatic phospholipid biosynthesis. If so, it will then be important to determine the mechanism which regulates developmental changes to hepatic phospholipid metabolism and the effect of variations in this process between individuals on tissue maturation and subsequent function.

\section{REFERENCES}

[1] Litman BJ, Mitchell DC. A role for phospholipid polyunsaturation in modulating membrane protein function. Lipids 1996, 31 (Suppl): S193-S197.

[2] Mitchell DC, Straume M, Litman BJ. Role of $s n-1$ saturated, $S n-2$ polyunsaturated phospholipids in control of membrane receptor conformational equilibrium: effects of cholesterol and acyl chain unsaturation on the metarhodopsin I $\phi$ metarhodopsin II equilibrium. Biochemistry 1992, 31: 662-670.

[3] Bayon Y, Croset M, Daveloose D, Guerbette F, Chirouze V, Viret J, Kader JC, Lagarde M. Effect of specific phospholipid molecular species incorporated in human platelet membranes on thromboxane A2/prostaglandin $\mathrm{H} 2$ receptors. J Lipid Res 1995, 36: 47-56.
[4] Burdge GC, Hunt AN, Postle AD. Mechanisms of hepatic phosphatidylcholine synthesis in adult rat: effects of pregnancy. Biochem J 1994, 303: 941-947.

[5] Burdge GC, Kelly FJ, Postle AD. Synthesis of phosphatidylcholine in guinea-pig fetal lung involves acyl remodelling and differential turnover of individual molecular species. Biochim Biophys Acta 1993, 1166: 251-257.

[6] Burdge GC, Kelly FJ, Postle AD. Mechanisms of hepatic phosphatidylcholine synthesis in the developing guinea pig: contributions of acyl remodelling and of N-methylation of phosphatidylethanolamine. Biochem J 1993, 290: 67-73.

[7] Samborski RW, Ridgway ND, Vance DE. Evidence that only newly made phosphatidylethanolamine is methylated to phosphatidylcholine and that phosphatidylethanolamine is not significantly deacylated-reacylated in rat hepatocytes. J Biol Chem 1990, 265: 18322-18329.

[8] Ridgway ND, Vance DE. Specificity of rat hepatic phosphatidylethanolamine N-methyltransferase for molecular species of diacyl phosphatidylethanolamine. J Biol Chem 1988, 263: 16856-16863.

[9] Burdge GC, Postle AD. Phospholipid molecular species composition of developing fetal guinea pig brain. Lipids 1995, 30: 719-724.

[10] Hunt AN, Kelly FJ, Postle AD. Developmental variation in whole human lung phosphatidylcholine molecular species: a comparison with guinea pig and rat. Early Hum Dev 1991, $125,157-171$.

[11] Vance JE, Vance DE. The role of phosphatidylcholine biosynthesis in the secretion of lipoproteins from hepatocytes. Can J Biochem Cell Biol 1985, 63: 870-881.

[12] Burdge GC, Postle AD. Hepatic phospholipid molecular species in the guinea pig. Adaptations to pregnancy. Lipids 1994, 29: 259-264.

[13] Postle AD, Al MD, Burdge GC, Hornstra G. The composition of individual molecular species of plasma phosphatidylcholine in human pregnancy. Early Hum Dev 1995, 43: 47-58.

[14] Carlson SE, Rhodes PG, Rao VS, Goldgar DE. Effect of fish oil supplementation on the n-3 fatty acid content of red blood cell membranes in preterm infants. Pediatr Res 1987, 21: 507-510.

[15] Maurage C, Guesnet P, Pinault M, Rochette de Lempdes J, Durand G, Antoine J, Couet C. Effect of two types of fish oil supplementation 
on plasma and erythrocyte phospholipids in formula-fed term infants. Biol Neonate 1998, 74: 416-429.

[16] Guesnet P, Pugo-Gunsam P, Maurage C, Pinault M, Giraudeau B, Alessandri JM, Durand G, Antoine JM, Couet C. Blood lipid concentrations of docosahexaenoic and arachidonic acids at birth determine their relative postnatal changes in term infants fed breast milk or formula. Am J Clin Nutr 1999, 70: 292-298.

[17] Bligh EG, Dyer W.J. A rapid method for total lipid extraction and purification. Can J Biochem Physiol 1959, 37: 912-917.

[18] Hunt AN, Burdge GC, Postle AD. Phospholipid composition of neonatal guinea pig liver and plasma: effect of postnatal food restriction. Lipids 1996, 31: 489-495.

[19] Caesar PA, Wilson SJ, Normand CS, Postle AD. A comparison of the specificity of phosphatidylcholine synthesis by human fetal lung maintained in either organ or organotypic culture. Biochem J 1988, 253: 451-457.

[20] Wright SM, Hockey PM, Enhorning G, Strong P, Reid KB, Holgate ST, Djukanovic $\mathrm{R}$, Postle AD. Altered airway surfactant phospholipid composition and reduced lung function in asthma. J Appl Physiol 2000, 89: 12831292.

[21] Han XL, Gross RW. Structural determination of picomole amounts of phospholipids via electrospray ionization tandem mass spec- trometry. J Am Soc Mass Spectrom 1995, 6: 1202-1210.

[22] Hajra AK. Glycerolipid biosynthesis in peroxisomes (microbodies). Prog Lipid Res 1995, 34: 343-364.

[23] Oscarsson J, Jansson JO, Eden S. Plasma pattern of growth hormone regulates sexual differentiation of phosphatidylcholine in rat plasma. Acta Physiol Scand 1988, 133: 257 265.

[24] Oscarsson J, Eden S. Sex differences in fatty acid composition of rat liver phosphatidylcholine are regulated by the plasma pattern of growth hormone. Biochim Biophys Acta 1988 , 959: 280-287.

[25] Connor WE, Lin DS, Neuringer M. Biochemical markers for puberty in the monkey testis: desmosterol and docosahexaenoic acid. J Clin Endocrinol Metabol 1997, 82: 1911-1916.

[26] Salem N, Niebylski CD. The nervous system has an absolute molecular species requirement for proper function. Mol Membr Biol 1995, 12: 131-134.

[27] Snyder F, Hibbs M, Malone B. Enzymatic synthesis of O-alkyl glycerolipids in brain and liver of rats during fetal and postnatal development. Biochim Biophys Acta 1971, 231: 409-411.

[28] Lomard M-N, Izzo AA, Benhaddi M, Natoour J, Benveniste J. Liver and plasma concentrations in paf-acether and its precursors after partial hepatectomy. Cell Prolif 1996, 29: 33-41. 